\title{
The incidence of myelodysplastic syndromes in Western Greece is increasing
}

\author{
Christina Avgerinou • Yannis Alamanos • \\ Panagiotis Zikos • Polyxeni Lampropoulou • \\ Maria Melachrinou • Vassiliki Labropoulou • \\ Ioannis Tavernarakis • Anthi Aktypi • Panagiotis Kaiafas • \\ Christos Raptis • Alexandra Kouraklis • \\ Marina Karakantza • Argiris Symeonidis
}

Received: 18 November 2012 / Accepted: 15 February 2013 /Published online: 10 April 2013

(C) The Author(s) 2013. This article is published with open access at Springerlink.com

\begin{abstract}
Descriptive epidemiology of the myelodysplastic syndromes (MDS) is always interesting and may reveal timedependent and geographical variations, as well as occupational exposure. Epidemiological data in Greece are not available by now. We have collected and analyzed medical records of all patients with a documented diagnosis of MDS, performed by an expert hematologist and/or hematopathologist, in the geographical area of Western Greece, during the 20-year period, defined between 1990 and 2009. We have then calculated and described demographic and clinical features of the diagnosed MDS patient population, and assessed the incidence and prevalence rates of MDS in Western Greece, during the abovementioned period. A total of 855 patients with newly diagnosed MDS have been identified. Refractory anemia was the most common subtype in both FAB and WHO classification systems and in both genders. Del-5q and RARS were more
\end{abstract}

C. Avgerinou $\cdot$ I. Tavernarakis $\cdot$ M. Karakantza $\cdot$ A. Symeonidis $(\bowtie)$

Hematology Division, Department of Internal Medicine,

University of Patras Medical School, 26504 Rion,

Patras, Greece

e-mail: argiris.symeonidis@yahoo.gr

C. Avgerinou $\cdot$ Y. Alamanos

Department of Public Health,

University of Patras Medical School, 26504 Rion,

Patras, Greece

P. Zikos

Department of Hematology,

"St Andrew" General Hospital of Patras, Tsertidou Str. No 1,

Patras 263.35, Greece

P. Lampropoulou $\cdot$ V. Labropoulou $\cdot$ A. Kouraklis

Hematology Division, Department of Internal Medicine,

University Hospital of Patras, 26504 Rion,

Patras, Greece commonly encountered among females, and the dysplastic subtype of chronic myelomonocytic leukemia among males. Trisomy 8 was the most common single cytogenetic abnormality. The crude mean annual incidence rate of MDS was 6.0 per 100,000 inhabitants aged $\geq 15$ years old (all subtypes according to $\mathrm{FAB}$ ), and it was 4.8 per 100,000 when CMML and RAEB-T were excluded. Crude incidence rate was higher in rural than in urban areas, but this finding was not confirmed after age standardization. Age-standardized mean annual incidence rate in men was $7.9 / 100,000$ and in women 3.4/100,000. A continuously increasing incidence rate of MDS has been observed throughout the study period.

Keywords Myelodysplastic syndromes · Epidemiology · Incidence $\cdot$ Classification $\cdot$ Western Greece

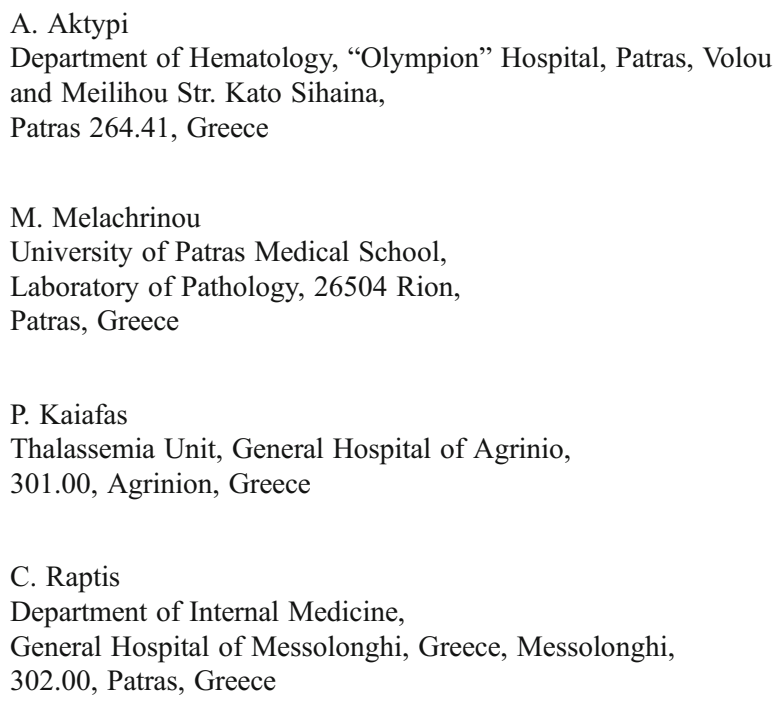

P. Kaiafas

Thalassemia Unit, General Hospital of Agrinio,

301.00, Agrinion, Greece

C. Raptis

Department of Internal Medicine,

General Hospital of Messolonghi, Greece, Messolonghi,

302.00, Patras, Greece 


\section{Introduction}

Myelodysplastic syndromes (MDS) are acquired clonal hematopoietic stem cell disorders, characterized by ineffective hematopoiesis, peripheral blood cytopenias, and increased risk of leukemic transformation. The incidence of MDS is not worldwide known, and this is attributed to many reasons. First, there are frequent diagnostic inconsistencies, leading to erroneous classification of many cases with borderline features, as other diseases, such as aplastic anemia, anemia of inflammation, myeloproliferative neoplasms, and acute myelogenous leukemia. Second, there is occasional difficulty in making the correct diagnosis, especially when morphologic features are subtle or inadequate [1]. Indeed, dysplastic features in the peripheral blood or bone marrow (BM) may accompany a large number of chronic diseases or conditions, particularly in the elderly, of inflammatory, endocrine, autoimmune, or neoplastic etiology, or they may be a consequence of advanced age alone [2]. Third, the diagnosis of MDS in very elderly patients may not be confirmed, due to reluctance of patients and/or physicians to perform a BM examination [3]. Another reason for lacking data is that systemic registration of MDS has only recently been started, even in countries with well-organized and active cancer registries.

The incidence of MDS varies significantly by geographical area, and this has been attributed to genetic, occupational, lifestyle, and environmental factors, not fully elucidated as yet [4]. According to published epidemiological studies, the mean annual incidence varies between 1/100,000 inhabitants in Japan [5] and 12.6 in the area of Bournemouth, UK (19811990) [6]. Data on the incidence and prevalence of MDS in Greece have not been published by now.

The objective of the present study was to describe demographic and clinical features of patients with MDS in Western Greece, during the previous two decades, and to estimate incidence and prevalence rates in a demographically well-defined population of the same area.

\section{Materials and methods}

Western Greece is defined geographically as the area southern of Epirus, western of Fokida and Eurytania in the Greek mainland, as well as western of Korinthia and Arcadia, and northern of Messinia in Peloponnese (Fig. 1). In this area, consisting of three prefectures, Achaia, Ilia, and Etolia and Akarnania, there is one major, fully occupied hospital-referral center, the University Hospital of Patras, a second major, referral hospital, "St Andrew" Hospital, and two smaller hospitals with a Department of Hematology. The University Hospital possesses an expert Hematopathology laboratory and accepts patients from the whole area, referred by physicians of smaller hospitals and private practice. Patients are
Fig. 1 Map of Greece, where the area of Western Greece (prefectures of Achaia, Ilia, and Etolia/Akarnania) is depicted in yellow (inserted picture). In the enlarged map of Western Greece, the red rectangle indicates the urban area of Patras, regional capital of Western Greece. The yellow arrow depicts the position of the Rion-Antirion bridge, which connects Peloponnese with continental Greece

also referred from neighbor territories, such as the Ionian islands (Kefallinia, Zakynthos, Ithaca, and Lefkas), and the closest parts of Korinthia, Fokida, and Messinia. In our area patients with hematological dyscrasias are not treated or followed by other specialists or private practice centers.

Medical records and electronic databases of the four above-mentioned hospitals were reviewed, and all patients with MDS diagnosed between 1.1.1990 and 31.12.2009 were registered. Only patients with a documented diagnosis of MDS, confirmed by BM examination (aspiration and/or biopsy), were included in the analysis. The study has been approved by the Ethical and Scientific Council of the participating hospitals.

Demographic data, as well as disease information (FAB and WHO classification, cytogenetics, laboratory findings at diagnosis, IPSS, transfusion dependency, WPSS, and leukemic evolution) were collected and analyzed for all patients (aged $\geq 15$ years) diagnosed during the study period. Pediatric MDS cases have not been included in this analysis.

Patients residing in the three prefectures of Western Greece were then selected for the estimation of epidemiological indices. The adult population of the area was considered stable during the study period and consisted of 603,543 inhabitants. Demographic data were based on the 2001 national census, provided by the General Secretariat of the Hellenic Statistical Authority.

\section{Statistical analysis}

Statistical analysis was performed by using the Statistical Software IBM SPSS Statistics 20. $t$ test (Student's test) was used for the comparison of means, Chi square $\left(\chi^{2}\right)$ test for the comparison of percentages between subgroups, and analysis of variance was performed to compare means between several subgroups. The comparison of agestandardized incidence rates was performed using the comparative morbidity figure (CMF). The standard error and $95 \%$ confidence intervals $(95 \% \mathrm{CI})$ of CMF were calculated according to the method of Breslow and Day $[7,8]$.

\section{Results}

Demographic features

Totally, 855 patients were diagnosed with an MDS between 1.1.1990 and 31.12.2009 in Western Greece. Among them, 


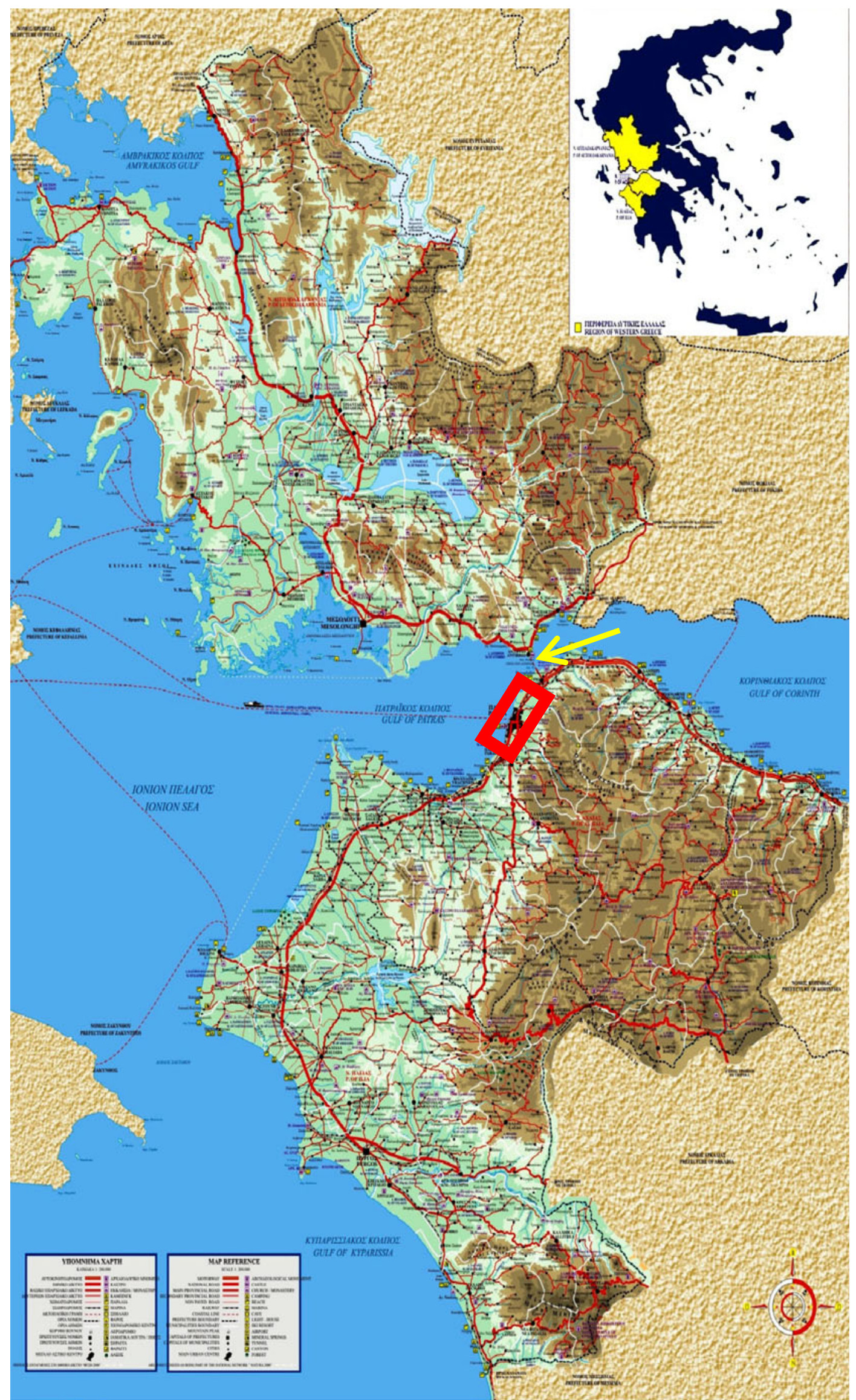


$606(71 \%)$ were males and 249 (29\%) females (M/F ratio 2.43:1). Mean age at diagnosis was $73.1 \pm 18.9$ years (median 74) and it was not significantly different between men and women, in each MDS subtype, and overall. However, age at diagnosis was significantly different by FAB subtype, and patients with RAEB-T were younger $(p=0.008)$.

Among the 855 patients, $721(84.3 \%)$ were living in Western Greece [Achaia $(N=371)$, Ilia $(N=175)$, Etolia/Akarnania $(N=175)]$, and $134(15.7 \%)$ in neighbor prefectures, [Kefallinia and Zakynthos $(N=41)$, Korinthia $(N=28)$, Fokida $(N=15)$, Messinia $(N=14)$, and other $(N=$ $36)]$. Four hundred and eighty-three patients $(56.7 \%)$ were living in rural or semi-urban areas, whereas 341 (39.9\%) resided in urban areas. For 29 patients $(0.3 \%)$ the area of residence was unknown.

Occupation was known in 640 patients $(75 \%)$ and almost half of them were farmers $[N=279(44 \%)]$. Other frequently encountered occupations were housekeeping $[N=84(13 \%)]$, merchantry $[N=37(6 \%)]$, public administration $[N=21(3 \%)]$, industrial worker $[N=21(3 \%)]$, policeman $[N=16(2.5 \%)]$, office employee $[N=13(2 \%)$, and teacher $[N=12(2 \%)]$.

\section{Clinical and laboratory features}

Presenting symptoms were known in 597 patients $(70 \%)$ and the most common were fatigue in $330(55 \%)$, fever or infection in $88(15 \%)$, and bleeding in $50(8 \%)$. In 126 patients $(21 \%)$ diagnosis was suspected by routine blood tests, while they were completely asymptomatic.

Totally, 833 patients $(97.4 \%)$ had primary, and 22 (2.6\%) secondary or therapy-related MDS, following previous exposure to chemo-/radiotherapy. Moreover, 67 cases (7.8\%) were fibrotic MDS, based on their substantial increase of BM reticulin fibers, and additional $38(4.4 \%)$ had hypoplastic-type MDS (BM cellularity $\leq 30 \%$ ).

Baseline hematological parameters were available in 776 patients $(90.8 \%)$ and $63.5 \%$ had moderate to severe anemia (hemoglobin $<10 \mathrm{~g} / \mathrm{dl}$ ), $33.4 \%$ had neutropenia (ANC $<1.5 \times 10^{9} / \mu \mathrm{l}$ ), and $40.9 \%$ had thrombocytopenia (PLT $<100 \times 10^{9} / \mu \mathrm{l}$ ). Moreover, $35.4 \%$ of the patients had various bicytopenias and $12.1 \%$ were pancytopenic. The presence and the various combinations of cytopenias at diagnosis are summarized in Table 1.

\section{FAB and WHO classification}

The distribution according to FAB classification was as follows: refractory anemia (RA) 313 patients, RA with ringed sideroblasts (RARS) 82, RA with excess of blasts (RAEB) 287, RAEB in transformation (RAEB-T) 34, chronic myelomonocytic leukemia (CMML) 123, and unclassified MDS 16. RARS was more frequent in women, yet this difference was not statistically significant.
Table 1 Cytopenias and hematological parameters at diagnosis in 776 patients with MDS

\begin{tabular}{|c|c|c|}
\hline Cytopenia at diagnosis & $N(\%)$ & \\
\hline Anemia $(\mathrm{Hb}<10 \mathrm{~g} / \mathrm{dl})$ & $493(63.5)$ & \\
\hline Neutropenia $\left(\mathrm{ANC}<1,500 / \mathrm{mm}^{3}\right.$ ) & $259(33.4)$ & \\
\hline Thrombocytopenia $\left(\mathrm{PLT}<100,000 \mathrm{~mm}^{3}\right)$ & $317(40.9)$ & \\
\hline Anemia and neutropenia & $161(20.7)$ & \\
\hline Anemia and thrombocytopenia & $207(26.7)$ & \\
\hline Neutropenia and thrombocytopenia & $141(18.2)$ & \\
\hline Pancytopenia & $95(12.2)$ & \\
\hline Laboratory values at presentation & Mean & $P$ \\
\hline $\begin{array}{l}\text { Hemoglobin - men }(N=549) \\
\text { Hemoglobin - women }(N=227)\end{array}$ & $\begin{array}{l}9.6 \mathrm{~g} / \mathrm{dl} \\
9.1 \mathrm{~g} / \mathrm{dl}\end{array}$ & $<0.0001$ \\
\hline Hemoglobin—all patients & $9.5 \mathrm{~g} / \mathrm{dl}$ & \multirow[b]{2}{*}{0.096} \\
\hline $\begin{array}{l}\text { White blood cells - men } \\
\text { White blood cells-women }\end{array}$ & $\begin{array}{l}7.88 \times 10^{9} / 1 \\
6.66 \times 10^{9} / 1\end{array}$ & \\
\hline White blood cells-all patients & $7.52 \times 10^{9} / 1$ & \multirow[b]{2}{*}{0.191} \\
\hline $\begin{array}{l}\text { Abs. neutrophil count-men } \\
\text { Abs. neutrophil count-women }\end{array}$ & $\begin{array}{l}4.10 \times 10^{9} / 1 \\
3.55 \times 10^{9} / 1\end{array}$ & \\
\hline Abs. neutrophil count-all patients & $3.94 \times 10^{9} / 1$ & \multirow{3}{*}{0.156} \\
\hline $\begin{array}{l}\text { Platelet count-men } \\
\text { Platelet count-women }\end{array}$ & $\begin{array}{l}154 \times 10^{9} / 1 \\
169 \times 10^{9} / 1\end{array}$ & \\
\hline Platelet count - all patients & $158 \times 10^{9} / 1$ & \\
\hline
\end{tabular}

According to the WHO classification 176 patients had RA, $16 \operatorname{Del}(5 q)$ syndrome, 53 RARS, 122 refractory cytopenia with multilineage dysplasia (RCMD), 24 RCMD with ringed sideroblasts (RCMD-RS), 162 RAEB-1, 123 RAEB-2, 52 CMML-dysplastic (CMML-D), 71 CMML-proliferative (CMML-P), 16 other hybrid myelodysplastic/myeloproliferative disorders (MDS/MPD, including four with RARS-T), six unclassified MDS, and 34 AML. Del-5q syndrome $(p=0.006)$ and RARS $(p=0.039)$ were more frequent in women, whereas CMML-D was more common in men $(p=0.002$, Table 2$)$.

\section{Cytogenetic abnormalities}

Cytogenetic analysis was performed in 611 patients (71\%), but in $20(3.3 \%)$ it could not be assessed due to absence of metaphases. Therefore, karyotype was available in 591 patients and it was normal in 364 (61.6\%) and abnormal in 227 (38.4\%). The most commonly detected cytogenetic abnormalities were: trisomy $8(8.3 \%)$, loss of $\Upsilon(5.8 \%)$, and multiple $(\geq 3)$ or complex chromosomal abnormalities (7.6\%). Del(5q) was found in $2.7 \%$ and chromosome 7 abnormalities in $3 \%$ of the patients. Loss of chromosome $\mathrm{Y}$ was considered a clonal abnormality, when $>50 \%$ of a minimum of 20 metaphases analyzed were demonstrating $-Y$. The kind of the detected chromosomal abnormalities among the total population tested, as well as among patients with a detected abnormal karyotype, is demonstrated in Table 3. 
Table 2 Distribution according to FAB and WHO classification, IPSS, and WPSS
No significant difference between men and women, according to FAB and to IPSS was observed. Del-5q syndrome and RARS were more frequent in women ( $4 \%$ vs. $1 \%, p=$ 0.006 , and $8.8 \%$ vs. $5.1 \%, p=$ 0.039 , respectively), whereas CMML-D was more frequent in men $(7.8 \%$ vs. $2 \%, p=0.002)$. WPSS very low subgroup was more frequent in women $(36.2 \%$ vs. $26.8 \%, p=0.047)$, whereas intermediate subgroup was more frequent in men $(19.2 \%$ vs. $7.1 \%, p=0.001)$.

\begin{tabular}{|c|c|c|c|c|c|c|c|}
\hline Group & No. & Percent & Men & Percent & Women & Percent & $p$ value \\
\hline \multicolumn{8}{|l|}{ FAB classification } \\
\hline RA & 313 & 36.6 & 214 & 35.3 & 99 & 39.8 & 0.223 \\
\hline RARS & 82 & 9.6 & 51 & 8.4 & 31 & 12.4 & 0.073 \\
\hline RAEB & 287 & 33.6 & 212 & 35.0 & 75 & 30.1 & 0.170 \\
\hline RAEB-T & 34 & 4.0 & 23 & 3.8 & 11 & 4.4 & 0.277 \\
\hline CMML & 123 & 14.5 & 93 & 15.3 & 30 & 12.0 & 0.213 \\
\hline Unclassified & 16 & 1.9 & 13 & 2.1 & 3 & 1.2 & 0.447 \\
\hline \multicolumn{8}{|l|}{ WHO-2001 classification } \\
\hline RA & 176 & 20.66 & 121 & 20.0 & 55 & 22.1 & 0.491 \\
\hline $\operatorname{Del}(5 q)$ & 16 & 1.9 & 6 & 1.0 & 10 & 4.0 & 0.006 \\
\hline RCMD & 122 & 14.3 & 87 & 14.4 & 35 & 14.1 & 0.900 \\
\hline RARS & 53 & 6.2 & 31 & 5.1 & 22 & 8.8 & 0.039 \\
\hline RCMD-RS & 24 & 2.8 & 16 & 2.6 & 8 & 3.2 & 0.649 \\
\hline RAEB-1 & 162 & 18.9 & 121 & 20.0 & 41 & 16.5 & 0.234 \\
\hline RAEB-2 & 123 & 14.4 & 91 & 15.0 & 32 & 12.9 & 0.415 \\
\hline AML & 34 & 4.0 & 24 & 4.0 & 10 & 4.0 & 0.277 \\
\hline CMML-D & 52 & 6.1 & 47 & 7.8 & 5 & 2.0 & 0.002 \\
\hline CMML-P & 71 & 8.3 & 46 & 7.6 & 25 & 10.0 & 0.241 \\
\hline MDS/MPD (incl. RARS-T) & 16 & 1.9 & 12 & 2.0 & 4 & 1.6 & 0.243 \\
\hline Unclassified/unknown & 6 & 0.5 & 4 & 0.7 & 2 & 0.8 & 0.741 \\
\hline Total & 855 & 100 & 606 & 100 & 249 & 100 & - \\
\hline \multicolumn{8}{|l|}{ IPSS risk group categorization } \\
\hline Low & 236 & 39.9 & 172 & 39.2 & 64 & 42.1 & 0.557 \\
\hline Intermediate-1 & 193 & 32.6 & 152 & 34.6 & 41 & 27.0 & 0.128 \\
\hline Intermediate- 2 & 105 & 17.8 & 76 & 17.3 & 29 & 19.1 & 0.622 \\
\hline High & 57 & 9.6 & 39 & 8.9 & 18 & 11.8 & 0.293 \\
\hline Subtotal & 591 & 100 & 439 & 100 & 152 & 100.0 & - \\
\hline Unknown IPSS & 264 & - & 167 & - & 97 & - & n.s. \\
\hline \multicolumn{8}{|c|}{ WPSS risk group categorization } \\
\hline Very low & 138 & 29.4 & 92 & 26.8 & 46 & 36.2 & 0.047 \\
\hline Low & 87 & 18.5 & 61 & 17.8 & 26 & 20.5 & 0.504 \\
\hline Intermediate & 75 & 16.0 & 66 & 19.2 & 9 & 7.1 & 0.001 \\
\hline High & 127 & 27.0 & 94 & 27.4 & 33 & 26.0 & 0.761 \\
\hline Very high & 43 & 9.1 & 30 & 8.8 & 13 & 10.2 & 0.620 \\
\hline Subtotal & 470 & 100 & 343 & 100 & 127 & 100.0 & - \\
\hline WPSS unknown & 207 & - & 132 & - & 75 & - & n.s. \\
\hline WPSS not applicable & 178 & - & 131 & - & 47 & - & n.s. \\
\hline Total & 855 & - & 606 & - & 249 & - & - \\
\hline
\end{tabular}

Prognostic classification according to IPSS and WPSS

IPSS could be assessed in 591 patients (69\%) and it was low in 236, intermediate-1 in 193, intermediate- 2 in 105 , and high in 57 patients. No difference in the distribution of men and women was found [low-(i.e., low/Int-1) vs. highrisk (i.e., Int-2/high)], $p=0.269$ ].

WPSS could be assessed in 470 patients. In 207 patients cytogenetic results were unavailable, and therefore the WPSS could not be calculated, whereas in additional 178,
WPSS was not applicable, either for a disease entity not assigned to the WHO classification (177), or for missing transfusion requirements (1). Patient distribution according to IPSS and WPSS is shown in Table 2.

Leukemic evolution

After a mean duration of dysplastic phase of 26 months (range 0.1-204 months), disease progressed to a more aggressive MDS or AML in 275 patients (32\%), whereas no progression 
Table 3 Cytogenetics in 591 patients with MDS

Italic figures demonstrate percentages among patients with an abnormal karyotype

\begin{tabular}{lllllll}
\hline Patient population: & \multicolumn{2}{l}{ All patients } & \multicolumn{5}{c}{ CMML and RAEBT excluded } \\
\hline Karyotype & $N$ & $\%$ & & $N$ & $\%$ & $(-)$ \\
Normal & 364 & 61.6 & $(-)$ & 294 & 60.7 & $(18.4)$ \\
Trisomy 8 & 49 & 8.3 & $(21.6)$ & 35 & 7.2 & $(14.7)$ \\
Loss of Y & 34 & 5.8 & $(15.0)$ & 28 & 5.8 & $(8.4)$ \\
Del(5q) & 16 & 2.7 & $(7.0)$ & 16 & 3.3 & $(6.3)$ \\
Del(20q) & 13 & 2.2 & $(5.7)$ & 12 & 2.5 & $(8.9)$ \\
Chromosome 7 aberrations & 18 & 3.0 & $(7.9)$ & 17 & 3.5 & $(1.6)$ \\
Trisomy 21 & 6 & 1.0 & $(2.6)$ & 3 & 0.6 & $(10.0)$ \\
Other single aberrations & 19 & 3.2 & $(8.4)$ & 19 & 3.9 & $(3.7)$ \\
Del(5q) plus add. abnormalities & 7 & 1.2 & $(3.1)$ & 7 & 1.4 & $(8.9)$ \\
Double abnormalities & 20 & 3.4 & $(8.8)$ & 17 & 3.5 & $(18.9)$ \\
Multiple/complex aberrations & 45 & 7.6 & $(19.8)$ & 36 & 7.4 & $(100.0)$ \\
Total & 591 & 100.0 & $(100.0)$ & 484 & 100.0 & \\
\hline
\end{tabular}

The age-specific mean annual incidence rate of MDS increased with age, starting from $0.1 / 100,000$ in the age group 15-39 years, 0.6 ( $40-49$ years), 2.1 (50-59 years), 10 (6069 years), 28.4 (70-79 years), and 34.7 in the age group $>80$ years (Table 6 ). There was a significant variation in the crude incidence rates among the different areas, which ranged from 2.8/100,000 inhabitants in the urban areas of Etolia and Akarnania to $8.8 / 100,000$ inhabitants in the rural areas of Achaia. Moreover, there was an increased incidence of MDS in Achaia in comparison to other prefectures (Table 7).

Given that the rural population is more senile than the urban, and that the incidence of MDS increases with age, we consequently performed a direct standardization method, to compare the incidence between rural and urban areas, by using as a standard population the whole adult population of Greece in 2001. Age-standardized incidence of MDS in rural areas was 5.9 (95\% CI 5.1-6.7) whereas, in urban areas was 5.2 (95\% CI 4.7-5.7). The CMF (ratio of incidence in rural/urban areas) was 1.13 (95\% CI 0.96-1.33). Therefore, we did not find a statistically significant difference in the incidence of MDS between rural and urban areas after age standardization. Crude incidence, as opposed to age-standardized incidence of MDS in rural and in urban areas, is depicted in Fig. 2. We also calculated age-standardized incidence rates of MDS for each prefecture, and the difference (incidence in Achaia, compared to that of the other prefectures) was even more remarkable. Age-standardized incidence of MDS in men was $7.9(95 \% \mathrm{CI}$ 7.1-8.7) and in women 3.4 (95\% CI 2.9-3.9). The CMF (ratio of incidence in men/women) was 2.32 (95\% CI 1.96-2.75). Sex-standardized incidence of MDS was 5.9 (95 \% CI 5.5-6.3) per 100,000 inhabitants (Table 7).

We finally estimated the temporal trends in the incidence in the same population throughout the study period, by dividing it in 5-year intervals. The number of new MDS cases gradually increased from 130 during the quinquennium 1990-1994, to 171 during 1995-1999, 190 during 2000-2004, and 
Table 4 Disease progression and evolution by MDS subtype according to FAB and WHO classification, and by IPSS and WPSS prognostic category

\begin{tabular}{|c|c|c|}
\hline FAB classification & Patients evolved & Percent \\
\hline RA & $39 / 282$ & 13.8 \\
\hline RARS & $20 / 76$ & 26.3 \\
\hline RAEB & $136 / 257$ & 52.9 \\
\hline RAEB-T & $27 / 33$ & 81.8 \\
\hline CMML & $48 / 114$ & 42.1 \\
\hline Unclassified & $5 / 16$ & 31.3 \\
\hline Total & $275 / 778$ & 35.3 \\
\hline Unknown & 77 & \\
\hline \multicolumn{3}{|l|}{ WHO classification } \\
\hline RA & $13 / 158$ & 8.2 \\
\hline $\operatorname{Del}(5 q)$ & $3 / 16$ & 18.8 \\
\hline RCMD & $23 / 110$ & 20.9 \\
\hline RARS & $5 / 49$ & 10.2 \\
\hline RCMD-RS & $15 / 22$ & 68.2 \\
\hline RAEB-1 & $70 / 150$ & 46.7 \\
\hline RAEB-2 & $65 / 106$ & 61.3 \\
\hline CMML-D & $19 / 50$ & 38.0 \\
\hline CMML-P & $29 / 64$ & 45.3 \\
\hline MDS/MPD & $8 / 16$ & 50.0 \\
\hline Unclassified & $1 / 6$ & 16.7 \\
\hline \multicolumn{3}{|l|}{ IPSS $(N=575)$} \\
\hline Low & $38 / 228$ & 16.7 \\
\hline Int-1 & $76 / 189$ & 40.2 \\
\hline Int-2 & $65 / 103$ & 63.1 \\
\hline High & $33 / 55$ & 60.0 \\
\hline \multicolumn{3}{|l|}{ WPSS $(N=444)$} \\
\hline Very low & $11 / 131$ & 8.4 \\
\hline Low & $18 / 81$ & 22.2 \\
\hline Intermediate & $33 / 77$ & 42.9 \\
\hline High & $69 / 114$ & 60.5 \\
\hline Very high & $18 / 41$ & 43.9 \\
\hline
\end{tabular}

eventually 230 during 2005-2009. The crude mean annual incidence rate increased from 4.3 (95\% CI 3.6-5.0) per 100,000 inhabitants in the first period (1990-1994), to 5.7 (95\% CI 4.9-6.6) during 1995-1999, 6.3 (95\% CI 5.4-7.2) during 2000-2004, and finally 7.6 (95\% CI 6.6-8.6) in the last period (2005-2009). Thus, a statistically significant increase of the overall incidence rate of MDS was observed throughout the study period. To elucidate which MDS subtypes mainly increased or whether all MDS subtypes proportionally increased, we calculated the crude mean annual incidence rates among patients with lower-risk MDS (FAB/RA-RARS), higher-risk MDS (RAEB/RAEBT/unclassified) and CMML separately. We found that the observed increase in the annual incidence of MDS in our area was almost entirely attributed to the lowerrisk MDS, whose incidence rose from 1.4/100,000 inhabitants in the first period (1990-1994) to $4.4 / 100,000$ in the last quinquennium 2005-2009, demonstrating $214 \%$ increase. The incidence of higher-risk MDS and of CMML was practically unchanged throughout the 20 -year period. The temporal trend of mean annual incidence rate of the whole MDS population and of the higher- and lower-risk cases, as well as that of CMML, through 1990-2009, is depicted in Fig. 3.

\section{Discussion}

Epidemiological studies on MDS are rare worldwide, but particularly in Greece there are no data about the epidemiology of these diseases. This is the first study which attempts to describe demographic and clinical features of patients with MDS, and to estimate incidence and prevalence rates in a well-defined geographical area of Greece.

A clear predominance of MDS in men has already been reported. In two studies male to female ratio was estimated 1.9 [9], and 1.62 [10], but in our study it was even higher (2.43). In our patient population the mean age at diagnosis was not significantly different between men and women, either overall or by subtype. In addition, there was a remarkably high representation of farmers. According to

Table 5 Comparison between evolution rates to AML by WHO subtype and by age

\begin{tabular}{|c|c|c|c|c|c|c|c|c|}
\hline WHO subtype & Total $N$ & Evolved $(N)$ & Percent & Not evolved $(N)$ & Percent & Unknown $(N)$ & Percent & $p$ value \\
\hline RA/RARS & 229 & 18 & 7.9 & 189 & 82.5 & 22 & 9.6 & \multirow[t]{2}{*}{$<0.0001$} \\
\hline RCMD/RCMD-RS & 162 & 41 & 25.3 & 106 & 65.4 & 15 & 9.2 & \\
\hline RAEB-1 & 162 & 70 & 43.2 & 80 & 49.4 & 12 & 7.4 & \multirow[t]{2}{*}{0.004} \\
\hline RAEB-2 & 123 & 65 & 52.8 & 41 & 33.3 & 17 & 13.8 & \\
\hline CMML-D & 52 & 19 & 36.5 & 31 & 59.6 & 2 & 3.8 & \multirow[t]{2}{*}{0.405} \\
\hline CMML-P & 71 & 29 & 40.8 & 35 & 49.3 & 7 & 9.6 & \\
\hline Other subtypes & 56 & 33 & 58.9 & 21 & 37.5 & 2 & 3.6 & - \\
\hline Age $<70$ years & 241 & 105 & 43.6 & 123 & 51.0 & 13 & 5.4 & \multirow[t]{2}{*}{$<0.0001$} \\
\hline Age $\geq 70$ years & 614 & 170 & 27.7 & 380 & 61.9 & 64 & 10.4 & \\
\hline
\end{tabular}


Table 6 Age-specific incidence rates of MDS in Western Greece, 1990-2009, by gender and by residence in a rural or urban area

\begin{tabular}{|c|c|c|c|c|c|c|c|c|c|c|}
\hline \multirow{2}{*}{$\frac{\text { Men and women }}{\text { Age group (years) }}$} & \multirow[b]{2}{*}{$N$} & \multirow[b]{2}{*}{ Rate } & \multicolumn{2}{|l|}{ Men } & \multicolumn{2}{|c|}{ Women } & \multicolumn{2}{|c|}{ Rural areas } & \multicolumn{2}{|c|}{ Urban areas } \\
\hline & & & $N$ & Rate & $N$ & Rate & $N$ & Rate & $N$ & Rate \\
\hline $15-39$ & 4 & 0.1 & 2 & 0.1 & 2 & 0.1 & 1 & 0.1 & 3 & 0.1 \\
\hline $40-49$ & 11 & 0.6 & 9 & 0.9 & 2 & 0.2 & 7 & 1.0 & 4 & 0.3 \\
\hline $50-59$ & 33 & 2.1 & 22 & 2.8 & 11 & 1.4 & 16 & 2.5 & 17 & 1.9 \\
\hline $60-69$ & 164 & 10.0 & 106 & 13.7 & 58 & 6.3 & 79 & 9.8 & 83 & 9.9 \\
\hline $70-79$ & 342 & 28.4 & 251 & 46.0 & 91 & 13.8 & 192 & 30.4 & 140 & 24.6 \\
\hline$\geq 80$ & 167 & 34.7 & 116 & 56.2 & 51 & 18.5 & 91 & 33.3 & 68 & 32.7 \\
\hline Total (crude) & 721 & 6.0 & 506 & 8.3 & 215 & 3.6 & 386 & 7.7 & 315 & 4.5 \\
\hline Total crude (CMML and RAEB-T excluded) & 585 & 4.8 & 405 & 6.7 & 180 & 3.0 & 309 & 6.1 & 260 & 3.7 \\
\hline
\end{tabular}

occupational data for the Hellenic population of Western Greece during 2007-2009 (provided by the Hellenic Statistical Authority), persons occupied with agricultural activities constituted $21 \%$, i.e., smaller than half of what we found. Nevertheless, a safe comparison cannot be made, because this percentage refers to persons of productive age, whereas our patients were mostly elderly and declared being farmers even after their retirement. This difference may also depict an under-representation of occupations associated with higher socioeconomic status, since some of these patients might have been treated in private centers of Athens. This possibility however may be valid only for a small minority of our patients. Alternatively, it could suggest a true association between MDS and agricultural activity, but the investigation of this hypothesis exceeds the limits of descriptive epidemiology.
We found that only $2.6 \%$ of the patients had secondary (therapy-related) MDS. This percentage is lower than what has been previously reported (5.3-12.5\%) [9, 11-13], although in a Spanish study no secondary MDS cases were identified [14]. The distribution according to FAB and WHO classification is consistent with the results of previous studies. All MDS subtypes, excluding Del-5q and RARS, were more frequent in men [15]. RARS was more frequent in women, in both classification systems, yet this difference was statistically significant only for the WHO classification. Conversely, CMML-D was significantly more frequent in men, as has been previously reported [16].

In our registry, karyotype is missing mostly in patients diagnosed in the early 1990s, and, generally, the later the diagnosis was made, the more cytogenetic studies are available, given the increased sensitization of experts about MDS. Loss of chromosome $\mathrm{Y}$ was highly represented, but

Table 7 Crude and age-standardized incidence rates of MDS in the population of people aged 15 years and older in Western Greece during the period 1990-2009 by prefecture, by rural, or urban area and by gender, comparative morbidity figures (CMF) and $95 \%$ confidence intervals

\begin{tabular}{llll}
\hline Subgroup & & Crude $(95 \% \mathrm{CI})$ & Age-standardized (95 \% CI) \\
\hline Prefecture & & & \\
Achaia & Rural areas & $8.8(7.3-10.3)$ & $7.2(5.9-8.5)$ \\
& Urban areas & $5.6(4.8-6.4)$ & $6.8(6.0-7.6)$ \\
& Overall & $6.9(6.2-7.6)$ & $7.3(6.6-8.0)$ \\
Ilia & Rural areas & $7.2(5.9-8.5)$ & $5.1(4.1-6.1)$ \\
& Urban areas & $3.7(2.7-4.7)$ & $4.1(3.1-5.1)$ \\
& Overall & $5.7(4.9-6.5)$ & $5.0(4.2-5.8)$ \\
Etolia and Akarnania & Rural areas & $7.0(5.8-8.3)$ & $5.2(4.2-6.2)$ \\
& Urban areas & $2.8(2.0-3.6)$ & $3.0(2.2-3.8)$ \\
Comparison between subgroups & Overall & $4.8(4.1-5.5)$ & $4.3(3.6-5.0)$ \\
All prefectures & Rural areas & $7.7(6.9-8.5)$ & $5.9(5.1-6.7)$ \\
& Urban areas & $4.5(4.0-5.0)$ & $5.2(4.7-5.7)$ \\
Gender & Men & $8.3(7.6-9.0)$ & $7.9(7.1-8.7)$ \\
& Women & $3.6(3.1-4.1)$ & $3.4(2.9-3.9)$ \\
All subgroups & Total & $6.0(5.6-6.4)$ & $5.7(5.3-6.1)$ \\
& Sex-standardized incidence rate (95 \% CI) & $5.9(5.6-6.3)$ &
\end{tabular}


Fig. 2 Comparison between crude and age-standardized incidence rate of MDS in rural and urban areas of SW Greece (1990-2009)
Age-standardized incidence rate

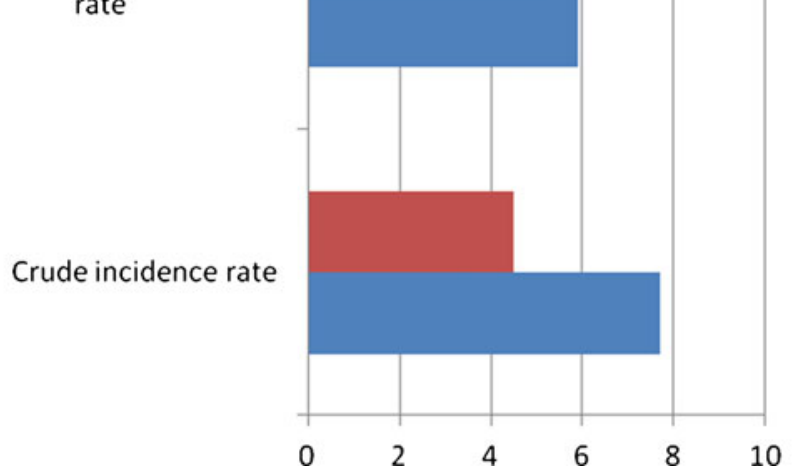

Urban areas

Rural areas surprisingly, an even higher representation of trisomy 8 was observed. $\operatorname{Del}(5 \mathrm{q})$ was the third most common single abnormality, and it should be marked that seven elderly patients, in whom Del-5q plus additional evolutionary clones were detected at baseline, were referred when their clinical situation had worsened. In these patients there was a period of macrocytic anemia, not requiring transfusions for 1-6 years before their referral, and therefore they might initially be true cases of Del-5q syndrome, diagnosed during disease progression. Distribution according to IPSS and WPSS as well as rate of leukemic transformation were in agreement with reports of previous studies [17] and were not significantly different in relation to gender, residence area, or geographical prefecture.

Incidence rates of MDS in Europe have been reported to vary between 2.1/100,000 inhabitants in the UK during 1984 1986 [18], 3.2 in France (1980-1990) [9], 3.5 in South Thames (1999-2000) [10], 3.6 in Sweden (1978-1982) [19], 4.1 (1975-1990) [11] and 4.9 (1996-2005) [13] in Germany (Düsseldorf), 7.7 in the Basque country (1993-1996) [12], 8.1 in Spain (1994-1998) [14], 9.3 in Somerset, UK [20], and 12.6 in Bournemouth, UK (1981-1990) [6]. A recent study from Romania found a very low incidence of $0.3 / 100,000$ [21]. In the United States the incidence of MDS has been reported 3.4/100,000 (SEER, 2001-2003) [22] and 3.3/100,000 (SEER and NAACCR, 2001-2003) [23]. However, recent studies suggest that many MDS cases are undetected by cancer registries and constructed algorithms, and that the true incidence of MDS might be higher [24]. Accordingly, the incidence of MDS in a non-profit healthcare system in western Washington State rose from 6.9 to 10.2 when possible MDS cases were identified from chart review [25]. Finally, a study in Japan reported a very low incidence rate of 1/100,000 inhabitants [26]. The comparison of the various incidence rates is difficult, because of great differences in age (excluding pediatric MDS cases leads to higher incidence rate), in classification (American studies have adopted ICD classification of MDS), and in time (starting 30 years ago but not referring to the same period, Table 8).

\section{Mean Annual Incidence Rates (new cases/100,000 inhabitants)} annual incidence rates of MDS in SW Greece through 19902009 in 5-year periods

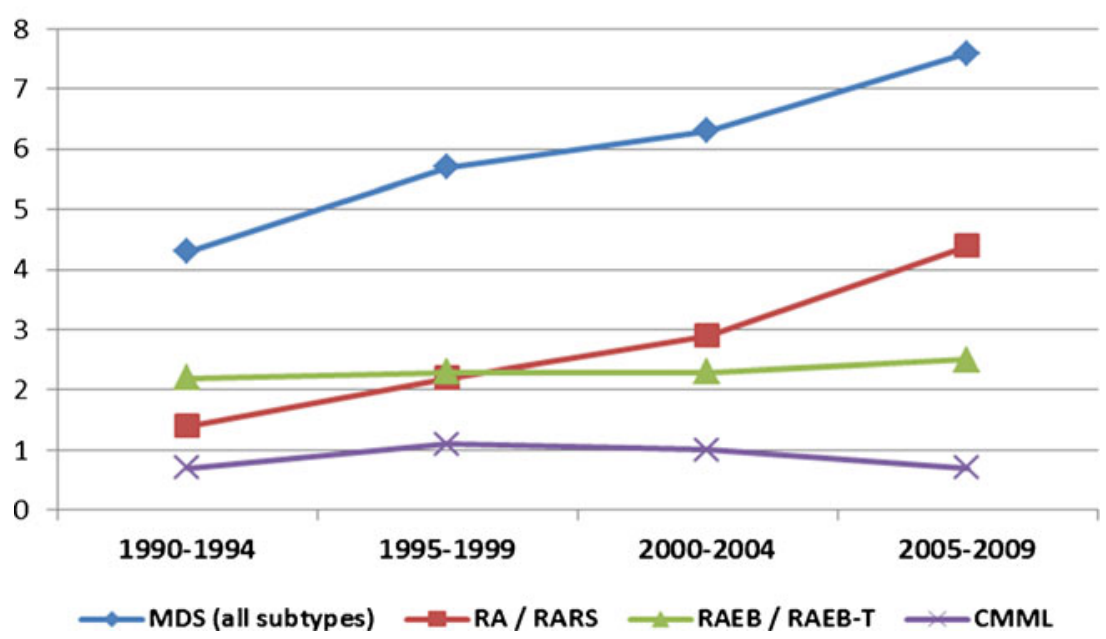


Table 8 Comparison between incidence rates of MDS from several epidemiologic studies

\begin{tabular}{|c|c|c|c|c|c|c|}
\hline Authors & Country (area) & $\begin{array}{l}\text { Population } \\
\text { (inhabitants) }\end{array}$ & $\begin{array}{l}\text { Age of study } \\
\text { population }\end{array}$ & Period & $\begin{array}{l}\text { Type of MDS } \\
\text { included }\end{array}$ & $\begin{array}{l}\text { Incidence rate } \\
(95 \% \mathrm{CI}) \text { per } \\
100,000 / \text { year }\end{array}$ \\
\hline Radlund et al. [19] & Sweden (Jönköping) & 224,000 & $>19$ years old & 1978-1992 & FAB classification & $\begin{array}{l}3.2(1978-1982)] \\
4.1(1983-1987)] \\
3.6 \text { mean } \\
3.5(1988-1992)]\end{array}$ \\
\hline Maynadié et al. [9] & $\begin{array}{l}\text { France (Côte d' Or, } \\
\text { Burgundy) }\end{array}$ & 493,931 & All ages & $1980-1990$ & FAB classification & $\begin{array}{l}3.2 \text { (crude) } \\
1.7 \text { (age adjusted) }\end{array}$ \\
\hline Williamson et al. [6] & UK (Bournemouth) & 214,500 & & 1981-1990 & FAB classification & 12.6 (crude) \\
\hline $\begin{array}{l}\text { Cartwright RA- } \\
\text { Leukemia } \\
\text { Research Fund } \\
\text { Centre [18] }\end{array}$ & UK (East Dorset) & $11,000,000$ & & 1984-1986 & & 2.1 (age adjusted) \\
\hline Aul C et al. [10] & Germany (Düsseldorf) & 575,000 & & $1975-1990$ & FAB classification & $1.4-4.1$ (crude) \\
\hline Germing U et al. [29] & Germany (Düsseldorf) & 575,000 & & 1991-2001 & FAB classification & 4.9 (crude) \\
\hline Neukirchen J et al. [13] & $\begin{array}{l}\text { Germany } \\
\text { (Düsseldorf) }\end{array}$ & 575,000 & All ages & $2002-2005$ & $\begin{array}{l}\text { WHO classification } \\
\text { FAB classification }\end{array}$ & $\begin{array}{l}3.4 \text { (crude) } \\
4.15 \text { (crude) }\end{array}$ \\
\hline Shimizu H et al. [26] & Japan (nationwide) & $160,000,000$ & & Sept. 1991 & & 1.0 (crude) \\
\hline Bauduer et al. [12] & France (Pays Basque) & 290,000 & All ages & 1993-1996 & FAB classification & 7.7 \\
\hline Phillips MJ et al. [20] & UK (Somerset) & & & 1985-1993 & & 9.3 \\
\hline $\begin{array}{l}\text { Iglesias Gallego M } \\
\text { et al. [14] }\end{array}$ & Spain (Ourense) & 346,913 & All ages & 1994-1998 & FAB classification & 8.1 \\
\hline Phekoo J et al. [10] & UK (South Thames) & $5,499,841$ & $\geq 16$ years old & 1999-2000 & FAB classification & 3.5 \\
\hline Ma X et al. [22] & USA (SEER-17 regions) & $75,000,000$ & All ages & $2001-2003$ & ICD-O3 $_{\text {classification }}{ }^{\mathrm{a}}$ & $3.4(3.3-3.5)$ \\
\hline Rollison DE et al. [23] & USA (NAACCR, SEER) & $759,270,956$ & All ages & 2001-2004 & ICD-O3 $_{\text {classification }}{ }^{\mathrm{a}}$ & 3.3 \\
\hline Gologan R [21] & Romania (Bucharest area) & $5,560,566$ & $>16$ years old & 1985-2004 & FAB classification & 0.3 \\
\hline Present study & $\begin{array}{l}\text { Western Greece (Achaia, Ilia, } \\
\text { Etolia and Akarnania) }\end{array}$ & 603,543 & $\geq 15$ years old & 1990-2009 & $\begin{array}{l}\text { FAB classification } \\
\text { excluding } \\
\text { CMML/RAEB-T }\end{array}$ & $\begin{array}{l}6.0(5.6-6.4) \\
\quad \text { (crude) } \\
5.7(5.3-6.1) \\
\quad(\text { age adjusted) } \\
4.8(4.4-5.2)\end{array}$ \\
\hline
\end{tabular}

${ }^{\mathrm{a}} \mathrm{CMML}$ and RAEB-T excluded

The crude incidence rate of MDS was higher in rural than in urban areas, but this difference did not persist after age standardization. In contrast, another study found higher incidence of MDS in men residing in urban areas [9].

We also observed an increased incidence of MDS in Achaia, compared to the other prefectures, and this difference became more prominent after age standardization. Possible explanations might be the easier access of patients residing in Achaia to the referral centers, leading to minimization of under-diagnosed cases, and the declaration of Patras, capital of Achaia, and of the whole region of Western Greece, residential area of patients' relatives, as residential area of patients living in distantly located, particularly rural areas. This might have led to underestimation of the incidence in the other prefectures of the region, as this has been observed in the urban areas of Etolia/Akarnania. Other possible explanations might be the restricted access of distantly living inhabitants to specialized centers, and the empirical treatment of less severe cases by family physicians, thus evading correct diagnosis, and the movement of some patients to referral centers outside Western Greece, particularly in Athens, where their relatives live and work.

Increasing incidence of MDS has been reported by McNally et al. [27] and by Aul et al. [11, 28] during the first period of the Düsseldorf study, but incidence rate reached a plateau in 1986, without further increase during the second period (1991-2001) [29]. Neukirchen et al. also calculated the incidence of MDS in Düsseldorf during the period 1996-2005 and found no further increase in the period 2002-2005 [13]. In our study, a continuously increasing incidence of MDS has been observed throughout the 20-year period, but this entirely concerned the lower-risk categories. This could be attributed to a better quality of health care, provided to the elderly population, and consequently to the prolongation of life expectancy. Another most possible explanation might be the higher degree of suspicion 
and awareness of the primary medical care providers, probably also as a result of the broader use of automatic blood analyzers, and the increasing referral of early-MDS cases, for evaluation to the specialized Hematological Departments, cases which were not usually referred in the past. Alternatively, it could reflect a true increase, related to environmental factors. Therefore, further epidemiological research with case-control studies is required, in order to investigate the possible contribution of environmental, occupational, and lifestyle factors to the continuous increase of MDS, particularly of the lower-risk categories, in our area.

Conflict of interest The authors declare that they have no conflict of interest.

Open Access This article is distributed under the terms of the Creative Commons Attribution License which permits any use, distribution, and reproduction in any medium, provided the original author(s) and the source are credited.

\section{References}

1. Bennett JM (2002) The myelodysplastic syndromes. Pathobiology and clinical management. Marcel Dekker Inc, New York, p 15, Chapter 2

2. Lipschitz DA, Udupa KB, Milton KY, Thompson CO (1984) Effect of age on hematopoiesis in man. Blood 63:502-509

3. Germing U, Neukirchen J, Haas R (2008) The epidemiology of myelodysplastic syndromes. Clin Leukemia 2(Feb):34-38

4. Strom SS, Velez-Bravo V, Estey EH (2008) Epidemiology of myelodysplastic syndromes. Semin Hematol 45:8-13

5. Shimizu H, Matsushita Y, Aoki K, Nomura T, Yoshida Y, Mizoguchi H (1995) Prevalence of the myelodysplastic syndromes in Japan. Int J Hematol 61:17-22

6. Williamson PJ, Kruger AR, Reynolds PJ, Hamblin TJ, Oscier DG (1994) Establishing the incidence of myelodysplastic syndrome. Br J Haematol 87:743-745

7. Breslow NE, Day NE (1987) Rates and rate standardisation. In: Heseltine E, technical editor for IARC. Statistical methods in cancer research. Volume II-the design and analysis of cohort studies. Lyon: IARC Scientific Publications 48-79

8. Bouyer J, Hemon D, Cordier S, Derrienic F, Stucker I, Stengel B, Clavel J (1993) Standardisation des mesures de risque et d'association. In: Epidémiologie. Principes et méthodes quantitatives. Paris: Les editions INSERM 209-226

9. Maynadié M, Verret C, Moskovtchenko P, Mugneret F, Petrell T, Caillot D, Carli PM (1996) Epidemiological characteristics of myelodysplastic syndromes in a well-defined French population. Br J Cancer 74:288-290

10. Phekoo KJ, Richards MA, Moller H, Schey SA (2006) The incidence and outcome of myeloid malignancies in 2,112 adult patients in South East England. Haematologica 91:1400-1404

11. Aul C, Gattermann N, Schneider W (1992) Age-related incidence and other epidemiological aspects of myelodysplastic syndromes. Br J Haematol 82:358-367
12. Bauduer F, Ducout L, Dastugue N, Capdupuy C, Renoux M (1998) Epidemiology of myelodysplastic syndromes in a French general hospital of the Basque country. Leuk Res 22:205-208

13. Neukirchen J, Schoonen WM, Strupp C, Gattermann N, Aul C, Haas R, Germing U (2011) Incidence and prevalence of myelodysplastic syndromes: data from the Düsseldorf MDS registry. Leuk Res 35:1591-1596

14. Iglesias Gallego M, Sastre Moral JL, Gayoso Diz P, Garcia Costa A, Ros Forteza S, Mayan Santos JM (2003) Incidence and characteristics of myelodysplastic syndromes in Ourense (Spain) between 1994-1998. Haematologica/Journal of Hematology 88:1197-1199

15. Van den Berghe H, Vermaelen K, Merucci C, Barbieri D, Tricot G (1985) The 5q-anomaly. Cancer Genet Cytogenet 17:189-225

16. Ribera JM, Cervantes F, Rozman C (1987) A multivariate analysis of prognostic factors in chronic myelomonocytic leukemia according to the FAB criteria. Br J Haematol 65:307-311

17. Greenberg P, Cox C, LeBeau MM et al (1997) International scoring system for evaluating prognosis in myelodysplastic syndromes. Blood 89:2079-2088

18. Cartwright RA (1992) Incidence and epidemiology of the myelodysplastic syndromes. In: Mufti GJ, Galton DAG (eds) The myelodysplastic syndromes. Churchill Livingstone, Edinburgh, pp 23-31

19. Radlund A, Thiede T, Hansen S, Carlsson M, Engquist L (1995) Incidence of myelodysplastic syndromes in a Swedish population. Eur J Haematol 54:153-156

20. Phillips MJ, Cull GM, Ewings M (1994) Establishing the incidence of myelodysplasia syndrome. Br J Haematol 88:896-897

21. Gologan R (2010) Demo-geographical data of myelodysplastic syndrome based on a large sample of patients from a Romanian Hematological Center. J BUON 15:547-555

22. Ma X, Does M, Raza A, Mayne ST (2007) Myelodysplastic syndromes: incidence and survival in the United States. Cancer 109:1536-1542

23. Rollison DE, Howlader N, Smith MT, Strom SS, Merrit WD, Ries LA, Edward BK, List AF (2008) Epidemiology of myelodysplastic syndromes and chronic myeloproliferative disorders in the United States, 2001-2004, using data from the NAACCR and SEER programs. Blood 112:45-52

24. Cogle CR, Craig BM, Rollison DE, List AF (2011) Incidence of the myelodysplastic syndromes using a novel claims-based algorithm: high number of uncaptured cases by cancer registries. Blood 117:7121-7125

25. De Roos AJ, Deeg HJ, Onstad L, Kopecky KJ, Aiello EJ, Yong M, Fryzek J, Davis S (2010) Incidence of myelodysplastic syndromes within a nonprofit healthcare system in western Washington state 2005-2006. Am J Hematol 85:765-770

26. Shimizu H, Matsushita Y, Aoki K, Nomura T, Yoshida Y, Mizoguchi H (1995) Prevalence of the myelodysplastic syndromes in Japan. Int J Hematol 61:17-22

27. McNally RJQ, Roman E, Cartwright RA (1999) Leukemias and lymphomas: time trends in the UK, 1984-93. Cancer Causes Control 10:35-42

28. Aul C, Giagounidis A, Germing U (2001) Epidemiological features of myelodysplastic syndromes: results from regional cancer surveys and hospital-based statistics. Int J Hematol 73:405-410

29. Germing U, Strupp C, Kundgen A, Bowen D, Aul C, Haas R, Gattermann N (2004) No increase in age-specific incidence of myelodysplastic syndromes. Haematologica 89:905-910 